\title{
Reaction of Primary Aromatic Amines with Alkyl Carbonates over NaY Faujasite: A Convenient and Selective Access to Mono-N-alkyl Anilines
}

\author{
Maurizio Selva,* Pietro Tundo, and Alvise Perosa \\ Dipartimento di Scienze Ambientali del'U niversità Ca' F oscari, \\ Calle Larga S. Marta, 2137-30123 - Venezia, I taly \\ selva@univeit
}

Received May 1, 2000

\begin{abstract}
At atmospheric pressure and at $130-160{ }^{\circ} \mathrm{C}$, primary aromatic amines $\left(\mathrm{p}-\mathrm{XC}_{6} \mathrm{H}_{4} \mathrm{NH}_{2}, \mathrm{X}=\mathrm{H}, \mathrm{Cl}\right.$, $\mathrm{NO}_{2}$ ) are mono- $\mathrm{N}$-alkylated in a single step, with symmetrical and asymmetrical dialkyl carbonates [ROCOOR', $\mathrm{R}=\mathrm{Me}, \mathrm{R}^{\prime}=\mathrm{MeO}\left(\mathrm{CH}_{2}\right)_{2} \mathrm{O}\left(\mathrm{CH}_{2}\right)_{2} ; \mathrm{R}=\mathrm{R}^{\prime}=\mathrm{Et} ; \mathrm{R}=\mathrm{R}^{\prime}=$ benzyl; $\mathrm{R}=\mathrm{R}^{\prime}=$ allyl; $\mathrm{R}=$ $\left.\mathrm{Et}, \mathrm{R}^{\prime}=\mathrm{MeO}\left(\mathrm{CH}_{2}\right)_{2} \mathrm{O}\left(\mathrm{CH}_{2}\right)_{2}\right]$, in the presence of a commercially available NaY faujasite. No solvents are required. Mono- $\mathrm{N}$-alkyl anilines are obtained with a very high selectivity (90-97\%), in good to excellent yields (68-94\%), on a preparative scale. In the presence of triglyme as a solvent, the mono- $\mathrm{N}$-alkyl selectivity is independent of concentration and polarity factors. The reaction probably takes place within the polar zeolite cavities, and through the combined effect of the dual acidbase properties of the catalyst.
\end{abstract}

\section{Introduction}

The direct base-promoted, conventional mono- $\mathrm{N}$-al kylation of anilines with toxic and corrosive organic halides and sulfates ${ }^{1,2}$ raises environmental concerns. Besides, the major synthetic problem is competing bis- $\mathrm{N}$-alkylation, which leads to mixtures of secondary and tertiary amines that are very difficult to separate. ${ }^{1}$ This is especially true when highly reactive el ectrophilic compounds (methyl, ethyl, benzyl, and allyl alkylating agents) are used. ${ }^{3}$

Selective mono- $\mathrm{N}$-alkylations of aromatic amines have been reported by using other alkylating agents such as alcohols, ${ }^{4 a-c}$ alkyl formates, ${ }^{4 d}$ and tellurium derivatives; $;$ however, reaction conditions are often drastic (high temperature, sealed vessels, etc.) or reagents are not readily available.

To prevent overalkylation, tedious and expensive multistep methods have been devised in which partially protected anilines (amides and thiazoles) were alkylated with alkyl halides, ${ }^{5 a-c}$ dimethyl carbonate, ${ }^{5 d}$ and ortho esters. ${ }^{5 e}$

Conceptually different strategies to obtain mono-Nalkyl anilines indude (i) reduction of imines, ${ }^{6 a-d}$ amides, ${ }^{6 e-g}$

* To whom correspondence should be addressed. Phone: +3941 257 8687; Fax: +3941 2578620

(1) (a) Gibson, M. S. In The Chemistry of the Amino Group; Patai, S., Ed.; Interscience Pub.: London 1968; Chapter 2, pp 45-62. (b) Hyre, J . E.; Bader, A. R. J . Am. Chem. Soc. 1958, 80, 437. (c) Willson, F. G.; Wheeler, T. S. Organic Syntheses; Wiley: New York, 1941; Collect. Vol. I, p 102.

(2) (a) Ono, Y. PureAppl. Chem. 1996, 68, 367. (b) Selva, M.; Tundo, P. In Green Chemistry: Frontiers in Benign Chemical Synthesis and Processes; Anastas, P., Williamson, T., Eds.; Oxford University Press: Oxford: 1998; Ch. 5, pp 87-100.

(3) March, J . In Advanced Organic Chemistry, 4th ed.; Wiley: New York, 1991.

(4) (a) Watanabe, Y.; Tsuji, Y.; I ge, H.; Ohsugi, Y.; Ohta, T. J . Org. Chem. 1994, 49, 3359. (b) Sprinzak; Y. J . Am. Chem. Soc. 1956, 78, 3207. (c) Tanigawa, Y.; Murahashi, S.-I .; Moritani, I . Tetrahedron Lett. 1975, 471. (d) Kondo, T.; Tantayanon, S.; Tsuji, Y.; Watanabe, Y. Tetrahedron Lett. 1989, 4137. (e) Hu, N. X.; Aso, Y.; Otsubo, T.; Ogura, F. Tetrahedron Lett. 1988, 4949. oximes, ${ }^{\text {th }}$ aziridines, ${ }^{6 i}$ and vinyl derivatives, ${ }^{61}$ (ii) metalmediated alkylations, ${ }^{7 a-c}$ and (iii) nucleophilic aromatic substitutions. ${ }^{8 a-d}$

Such a massive experimental effort indicates that a convenient mono- $\mathrm{N}$-alkylation is an important synthetic goal. Our approach is based upon the idea of inducing selectivity by exploiting the steric demand of zeolite cavities. Sel ective mono- $\mathrm{N}$-alkylations of primary aromatic amines by alkyl halides have been claimed in the presence of both X-and Y-faujasites. ${ }^{9 a, b}$ Better results have been recently reported by others and by us, ${ }^{10 a-c}$ for the preparation of $\mathrm{N}$-methyl anilines with dimethyl carbonate (DMC) as the alkylating agent and alkali cation-exchanged zeolites as the catalysts (Scheme 1).

(5) (a) Katritzky, A. R.; Drewniak, M.; Aurrecoechea, J . M. J . Chem. Soc., Perkin Trans. 1 1987, 2539. (b) Carnahan, F. L.; Hurd, C. D. J . Am. Chem. Soc. 1930, 53, 4587. (c) Nordlander, J . E. et al. Tetrahedron Lett. 1978, 4987. (d) Lissel, M.; Rohani-Dezfuli, A. R.; Vogt, G.J . Chem Res. (S) 1989, 10, 312. (e) Roberts, R. M.; Vogt, P. J . J. Am. Chem. Soc. 1956, 78, 4778.

(6) (a) Shibata, I.; Suwa, T.; Sugiyama, E.; Baba, A. Synlett 1998 1081. (b) Verardo, G.; Giumanini, A. G.; Strazzolini, P.; Poiana, M. Synthesis 1993, 121. (c) Pelter, A.; Rosser, R. M.J . Chem. Soc, Perkin Trans. 1 1984, 717. (d) Feringa, B. L.; J ansen, J . F. G. A. Synthesis 1988, 184. (e) Narasimhan, S.; Madvahan, S.; Balakamur, R.; Swarnalakshmi, S. Synth. Commun. 1997, 27, 391. (f) Uchiyama, M. et al. J . Am. Chem. Soc. 1997, 119, 11425. (g) Krishnamurthy, S. Tetrahe dron Lett. 1982, 3315. (h) Sasatani, S.; Miyazaki, T.; Maruoka, K. Yamamoto, H. Tetrahedron Lett. 1983, 4711. (i) Almena, J .; F oubelo F.; Yus, M. J . Org. Chem. 1994, 59, 3210. (I) Capella, L.; M ontevecchi, P. C.; Navacchia, M. L. J . Org. Chem. 1995, 60, 7424.

(7) (a) Barton, D. H. R.; Doris, E. Tetrahedron Lett. 1996, 3295 (b) Yoshida, Y.; Tanabe, Y. Synthesis 1997, 533. (c) Bartoli, G.; Marcantoni, E.; Bosco, M.; Dal pozzo, R. Tetrahedron Lett. 1988, 2251.

(8) (a) Behr, L. C.; Kirby, J . E.; MacDonald, R. N.; Todd, C. W. J Am. Chem. Soc. 1946, 68, 1296. (b) I bata, T.; I sogami, Y.; Toyoda, J. Bull. Chem. Soc. J pn. 1991, 64, 42. (c) Kotsuki, H.; Kobayashi, S.; Suenaga, H.; Nishizawa, H. Synthesis 1990, 1145. (d) Katritzky, A. R.; Laurenzo, K. S. J . Org. Chem. 1988, 53, 3978.

(9) (a) Onaka, M.; I shikawa, K.; I zumi, Y.; Chem. Lett. 1982, 1783. (b) Onaka, M.; Umezono, A.; Kawai, M.; I zumi, Y. J . Chem. Soc., Chem. Commun. 1985, 1202.

(10) (a) Fu, Z.-H.; Ono, Y. Catal. Lett. 1993, 22, 277. (b) P. R. Hari Prasad Rao, Massiani, P.; Barthomeuf, D. Catal. Lett. 1995, 31, 115. (c) Selva, M.; Bomben, A.; Tundo, P. J. Chem. Soc., Perkin Trans. 1 1997, 1041. 
Scheme $1^{\mathrm{a}}$

$\mathrm{ArNH}_{2}+\mathrm{CH}_{3} \mathrm{OCOOCH} \stackrel{\mathrm{i}}{\longrightarrow} \mathrm{ArNHCH}_{3}+\mathrm{CH}_{3} \mathrm{OH}+\mathrm{CO}_{2}$

a (i) Y- or X-faujasites, $120-180{ }^{\circ} \mathrm{C} ; \mathrm{Ar}=\mathrm{Ph}, \mathrm{p}-\mathrm{O}_{2} \mathrm{NC}_{6} \mathrm{H}_{4}$ p-NCC $6 \mathrm{H}_{4}, 0-\mathrm{MeO}_{2} \mathrm{CC}_{6} \mathrm{H}_{4}, 2,6-\left(\mathrm{CH}_{3}\right)_{2} \mathrm{C}_{6} \mathrm{H}_{3}$.

According to Scheme 1, selectivity in the mono- $\mathrm{N}$ methylation was in the range of $92-98 \%$ at conversions up to $93 \%$ : N-methylaniline was obtained under both continuous-flow (c.-f.) ${ }^{10 a-b}$ and batch conditions, ${ }^{10 c}$ while heavier anilines were synthesized through batchwise reactions in an autoclave. ${ }^{10 c}$ Beside the excellent synthetic result, this alkylating procedure shows intrinsic environmental benefits. The use of safe solid catalysts (zeol ites) is coupled to a nontoxic compound (DMC), and the reaction does not require solvents and does not produce wastes to be disposed of, but only methanol.

We report herein a development of this methodology. At atmospheric pressure and at $130-160{ }^{\circ} \mathrm{C}$, several mono-N-alkyl anilines $\mathbf{l a}-\mathbf{n}\left(\mathrm{Z}-\mathrm{C}_{6} \mathrm{H}_{4} \mathrm{NHR} ; \mathrm{Z}=\mathrm{H}, \mathrm{p}-\mathrm{Cl}\right.$, $\mathrm{p}-\mathrm{NO}_{2} ; \mathrm{R}=\mathrm{Me}$; $\mathrm{Et} ; \mathrm{Bn}$; allyl) have been prepared through very selective and high-yielding batch reactions with unsymmetrical and symmetrical dialkyl carbonates $\mathbf{2 a}-\mathbf{e}$ [ROCOOR'; 2a: $\mathrm{R}=\mathrm{Me}, \mathrm{R}^{\prime}=\mathrm{MeO}\left(\mathrm{CH}_{2}\right)_{2} \mathrm{O}\left(\mathrm{CH}_{2}\right)_{2} ; \mathbf{2 b}: \mathrm{R}$ $=\mathrm{R}^{\prime}=\mathrm{Et} ; \mathbf{2 c}: \mathrm{R}=\mathrm{R}^{\prime}=\mathrm{PhCH}_{2} ; \mathbf{2 d}: \mathrm{R}=\mathrm{R}^{\prime}=\mathrm{CH}_{2}=$ $\mathrm{CHCH}_{2} ;$ 2e: $\left.\mathrm{R}=\mathrm{Et}, \mathrm{R}^{\prime}=\mathrm{MeO}\left(\mathrm{CH}_{2}\right)_{2} \mathrm{O}\left(\mathrm{CH}_{2}\right)_{2}\right]$, in the presence of a commercial $\mathrm{NaY}$ faujasite.

\section{Results and Discussion}

(i) Selective Mono-N-methylations. Under batch conditions, O-, C-, and $\mathrm{N}$-methylations with DMC took place at temperatures of $120-220{ }^{\circ} \mathrm{C}$ and required pressurized vessels (autoclaves) fitted with $\mathrm{CO}_{2}$-purging valves. ${ }^{11,12}$ The use of unsymmetrical alkyl methyl carbonates (2: $\mathrm{ROCOOCH}$ ) makes the reaction setup simpler. As we recently reported, ${ }^{13}$ at atmospheric pressure and in the presence of $\mathrm{K}_{2} \mathrm{CO}_{3}, \mathbf{2}\left(\mathrm{R} \geq\right.$ alkyl $\mathrm{C}_{3}$ ) are excellent O-methylating agents of phenols, yielding anisoles with up to $99 \%$ chemoselectivity.

On the basis of these results, unsymmetrical methyl carbonates were tested for $\mathrm{N}$-methylations. In particular, the reaction of aniline with 2-(2-methoxyethoxy)ethyl methyl carbonate [2a: $\mathrm{R}=\mathrm{Me}, \mathrm{R}^{\prime}=\mathrm{MeO}\left(\mathrm{CH}_{2}\right)_{2} \mathrm{O}\left(\mathrm{CH}_{2}\right)_{2}$ ] was investigated. A $0.45 \mathrm{M}$ triglyme solution of aniline ( $5 \mathrm{~mL}$ for each run $)^{14}$ was made to react with different amounts of $\mathbf{2 a}$ at atmospheric pressure. $\mathrm{NaY}$ or $\mathrm{K}_{2} \mathrm{CO}_{3}$ were used as the catalysts in a 1:1 weight ratio with respect to aniline. Table 1 reports the results.

In the presence of $\mathrm{NaY}$, at $115-150{ }^{\circ} \mathrm{C}$, the reaction of aniline with $\mathbf{2 a}$ proceeded with very good methyl selectivity. At conversions up to $100 \%, \mathrm{~N}$-methyl aniline (MA) was obtained, with only trace amounts $(\leq 1 \%)$ of the dimethyl derivative (DMA) (entries 1-6) (Scheme 2).

(11) (a) Selva, M.; Marques, C. A.; Tundo P. J . Chem. Soc., Perkin Trans. 1 1994, 1323. (b) Bomben, A.; Marques, C. A.; Selva, M.; Tundo, P. Tetrahedron 1995, 51, 11573. (c) Tundo, P.; Selva, M. Chemtech 1995, 25, 31. (d) Bomben, A.; Selva, M.; Tundo, P. J . Chem. Res. (M) 1997, 448. (e) Tundo, P.; Selva, M.; Bomben, A. Org. Synth. 1998, 76, 169.

(12) Under continuous-flow conditions, DMC-mediated methylations require substrates with a relatively high vapor tension in order to be fed into suitable plug-flow reactors (see ref 11d).

(13) Perosa, A.; Selva, M.; Tundo, P.; Zordan, F. Synlett 2000, 2, 72

(14) In the case of phenols, compound $\mathbf{2 a}$ yielded the higher O-methyl selectivity (<99\%), in the presence of triglyme as the solvent.
Scheme $2^{a}$

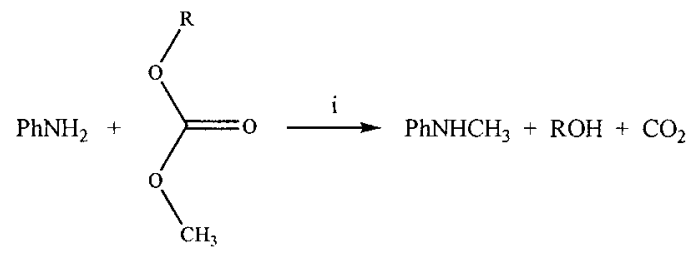

a (i) NaY, $115-130{ }^{\circ} \mathrm{C}$, triglyme as solvent. $\mathrm{R}=\mathrm{MeO}\left(\mathrm{CH}_{2}\right)_{2} \mathrm{O}$ $\left(\mathrm{CH}_{2}\right)_{2}$. Selectivity in the mono- $\mathrm{N}$-methylation was $>99 \%$.

Also, the competing $\mathrm{N}$-alkylation took place to a very small extent only at $150^{\circ} \mathrm{C}$ [PhNRMe: 2-3\%; R = MeO$\left(\mathrm{CH}_{2}\right)_{2} \mathrm{O}\left(\mathrm{CH}_{2}\right)_{2}$, entries 1 and 2, and 5 and 6]. The steric effect of the oxyethylenic chain $\left[\mathrm{MeO}\left(\mathrm{CH}_{2}\right)_{2} \mathrm{O}\left(\mathrm{CH}_{2}\right)_{2}-\right]$ of the alkylating agent seems to be the major discriminating factor between the two possible $\mathrm{N}$-alkylation paths. ${ }^{15}$ I $\mathrm{n}$ the case of phenols, the carbonate $\mathbf{2} \mathbf{a}$ behaves al so as an excellent $\mathrm{O}$-methylating agent with $\mathrm{K}_{2} \mathrm{CO}_{3}$ as the cataIyst. ${ }^{13}$ The $Y$-type faujasite has a crucial effect on the monomethyl selectivity of the reaction, through a combined effect of its dual acid-base properties and the size of its cavities. ${ }^{10 a-c, 16-17}$ Polar amino groups of anilines may strongly interact with the basic oxygens of the zeolite, while the electrophilic alkylating agent can be activated by the Lewis-acidic cations in the crystal lattice. In the case of batch methylations with DMC, the formation of carbamate intermediates (ArNHCOOMe) suggests that also an intermediate selectivity may operate.10c

The methylation rate increased with temperature (entries 2-4) and the $\mathbf{2 a}$ /aniline (W) mol ar ratio (entries 1 and 2, and 5 and 6). However, no rate improvement was achievable when the quotient $\mathrm{W}$ was $\geq 2$ (entries 1 and 2).

$\mathrm{K}_{2} \mathrm{CO}_{3}$ was totally ineffective to promote $\mathrm{N}$-methylation (entry 7).

To test the effect of the catalyst, a set of experiments was run with different amounts of NaY. Catalyst/aniline (Q) weight ratios of $0.1,0.2,0.5$, and 1 were used. Reactions were carried out at $130{ }^{\circ} \mathrm{C}$. A $1.6 \mathrm{M}$ solution ( $3 \mathrm{~mL}$ for each run) of aniline in triglyme reacted with $\mathbf{2 a}$ (2 molar equiv of with respect to aniline). Results are shown in Figure 1.

For $\mathrm{Q} \geq 1$, the reaction was substantially complete after $100 \mathrm{~min}$, while at $\mathrm{Q}$ ratios of 0.2 and 0.1 , aniline conversions of $94 \%$ and $83 \%$ (Figure 1a) were reached only after 650 and 500 min (Figure 1b), respectively: this remarkable increase of the reaction time can be ascribed to a saturation of the active sites of the zeolite, as reported al so for the mono-N-methylations with DMC. $10 \mathrm{c}$

The reaction selectivity was not affected by dilutionpolarity phenomena: methyl aniline was the sole product (conversion up to 95\%) when either $0.45 \mathrm{M}$ (Table 1, entry 3) or $1.6 \mathrm{M}$ solutions (Figure 1) were used. This fact contrasts the behavior of most alkylations of phenols and $\mathrm{CH}_{2}$-acidic compounds with alkyl carbonates, where selectivity is largely affected by solvent effects. ${ }^{11,13}$ I $n$ the case of amines, the determining factor is the high polarity of the zeolite cavities (the reactive site) which is scarcely modified by the solvent(s) used.

(ii) Selective Mono-N-alkylations. Since the methyl selectivity appeared independent of concentration and

15) Caldwell, G.; Magnera, T. F.; Kebarle P. J . Am. Chem. Soc. 1984, 106, 959.

(16) Narayanan, S.; Sultana, A. Appl. Catal. A. Gen. 1998, 167, 103.

(17) Barthomeuf, D. J . Phys. Chem. 1984, 88, 42. 
Table 1. Selective Mono-N-methylation of Aniline with $\left.\mathrm{ROCOOCH}_{3}\left[2 \mathrm{a}: \mathrm{R}=\mathrm{MeO}\left(\mathrm{CH}_{2}\right)_{2} \mathrm{O}_{(\mathrm{CH}}\right)_{2}\right]$ in the Presence of NaYa

\begin{tabular}{|c|c|c|c|c|c|c|c|c|}
\hline \multirow[b]{2}{*}{ entry } & \multirow[b]{2}{*}{$\mathrm{W}^{\mathrm{b}}(\mathrm{mol}: \mathrm{mol})$} & \multirow[b]{2}{*}{ catalyst $^{\mathrm{c}}$} & \multirow[b]{2}{*}{$\mathrm{T}\left({ }^{\circ} \mathrm{C}\right)$} & \multirow[b]{2}{*}{$\mathrm{t}(\min )$} & \multirow[b]{2}{*}{ convn $^{d}(\%)$} & \multicolumn{3}{|c|}{ products $(\%$, by GC) } \\
\hline & & & & & & PhNHMe & $\mathrm{PhN}(\mathrm{Me})_{2}$ & PhNRMe \\
\hline 1 & $4: 1$ & $\mathrm{NaY}$ & 150 & 90 & 100 & 97 & 1 & 2 \\
\hline 2 & $2: 1$ & & 150 & 90 & 100 & 96 & 1 & 3 \\
\hline 3 & & & 130 & 360 & 93 & 93 & & \\
\hline 4 & & & 115 & 610 & 90 & 90 & & \\
\hline 5 & 1.5:1 & & 150 & 120 & 95 & 93 & & 2 \\
\hline \multirow[t]{2}{*}{6} & $1.2: 1$ & & 150 & 180 & 93 & 90 & & 3 \\
\hline & & & 115 & 120 & - & & & \\
\hline \multirow[t]{2}{*}{7} & $2: 1$ & $\mathrm{~K}_{2} \mathrm{CO}_{3}$ & 130 & 120 & - & & & \\
\hline & & & 150 & 100 & - & & & \\
\hline
\end{tabular}

${ }^{\text {aAll }}$ reactions were carried out with a $0.43 \mathrm{M}$ solution $(5 \mathrm{~mL})$ of aniline in triglyme as solvent. bW: molar ratio between the carbonate $2 \mathrm{a}$ and aniline. $\mathrm{C}$ oth the catalysts ( $\mathrm{NaY}$ and $\mathrm{K}_{2} \mathrm{CO}_{3}$ ) were used in a $1: 1$ weight ratio with respect to aniline. ${ }^{\mathrm{d}}$ Aniline conversion determined by GC.
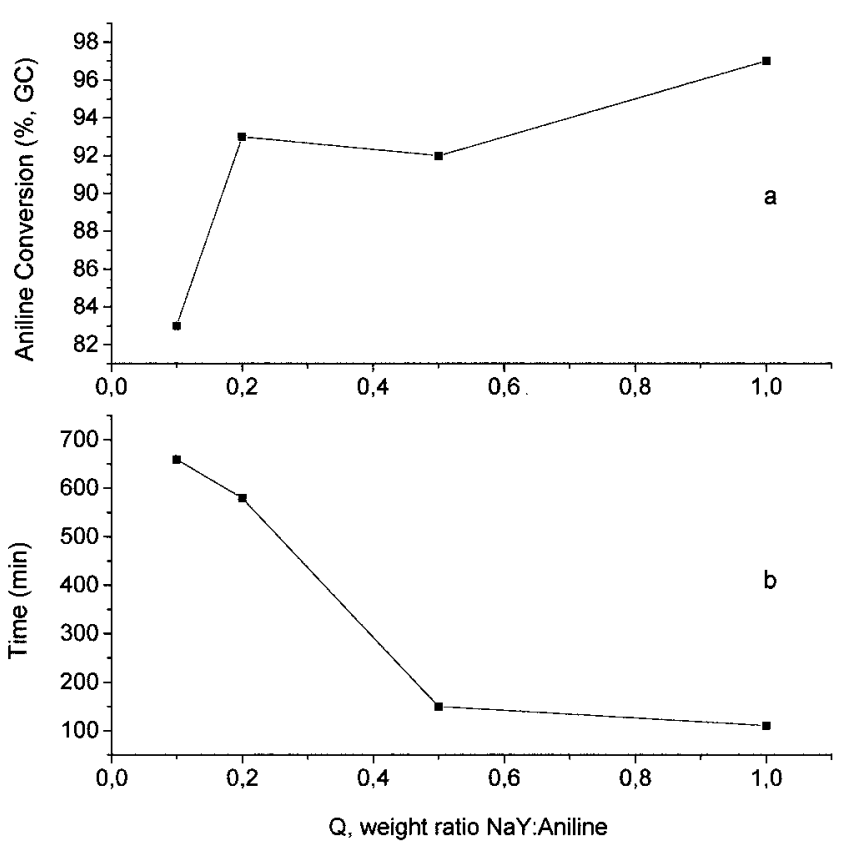

Figure 1. Effect of the catalyst amount over substrate conversion (a) and reaction time (b) on the mono- $\mathrm{N}$-methylation of aniline with carbonate $\mathbf{2 a}$ carried out at $130{ }^{\circ} \mathrm{C}$ with a $1.6 \mathrm{M}$ solution $(5 \mathrm{~mL}$ ) of the substrate in triglyme. PhNHMe was the sole reaction product. Although not shown, the increase of Q over 1 does not produce further enhancement of the reaction rate.

solvent polarity (Table 1 and Figure 1), the alkylation of different anilines $\left(\mathrm{Z}-\mathrm{C}_{6} \mathrm{H}_{4} \mathrm{NH}_{2} ; \mathrm{Z}=\mathrm{H}\right.$, p-Cl, p- $\left.\mathrm{NO}_{2}\right)$ was carried out neat with unsymmetrical (2a, 2e) and symmetrical (2b-e) organic carbonates, at atmospheric pressure and temperatures of $130-160{ }^{\circ} \mathrm{C}$, in the presence of NaY (0.5-1 weight ratio with respect to the amine) as the catalyst. All substrates were used on a gram scale $(0.5-3 \mathrm{~g})$, and $\mathrm{N}$-alkylated products were isolated. The results are reported in Table 2.

At $130{ }^{\circ} \mathrm{C}$, the reaction of aniline and $\mathbf{2 a}$ (in a 1:1.2 molar ratio) afforded methyl aniline with $98 \%$ selectivity. After 210 min, conversion was 95\%, and the product could be isolated in a $90 \%$ yield (entry 1 ). Under the same conditions $\left(130{ }^{\circ} \mathrm{C}, \mathrm{W}=1.2\right.$, and $\left.\mathrm{Q}=0.5\right)$, mono- $\mathrm{N}$-ethyl, -benzyl, and -allyl-aniline were also obtainable in high yields (84-94\%, entries 2-4), from diethyl, dibenzyl, and diallyl carbonates (2/b-d). Resonance effects should account for the faster reaction of dibenzyl and diallyl carbonates $(\mathbf{2} \mathbf{b}-\mathbf{d})$ with respect to diethyl carbonate (entries 2-4).
However, methylation with carbonate $\mathbf{2 a}$ (entry 1) was slower than ethylation with diethyl carbonate (entry 2).

Dialkyl carbonates $\mathbf{2 a}-\mathbf{e}$ behaved as excellent alkylating agents also for EWG deactivated amines: p-nitroand $\mathrm{p}$-chloro-aniline afforded the corresponding mono$\mathrm{N}$-alkyl derivatives $\left(\mathrm{Z}-\mathrm{C}_{6} \mathrm{H}_{4} \mathrm{NHR} ; \mathrm{Z}=\mathrm{p}-\mathrm{NO}_{2}, \mathrm{p}-\mathrm{Cl} ; \mathrm{R}=\right.$ $\mathrm{Me}, \mathrm{Et}, \mathrm{Bn}$, allyl) with high mono-alkyl selectivity (90$97 \%$ ) and good isolated yields (68-82\%) (entries 5-12) (Scheme 3).

Different aryl substituents are compatible with different organic carbonates, and the mono- $\mathrm{N}$-alkyl selectivity is very satisfactory in every case. The reactivity trend follows the nucleophilicity of the anilines: poorly nucleophilic amines ( $\mathrm{p}-\mathrm{NO}_{2}$ and $\mathrm{p}-\mathrm{Cl}$-anilines) required a higher $\mathrm{Q}$ ratio ( 1 vs 0.5 ) and/or a higher reaction temperature (140-160 ${ }^{\circ} \mathrm{C}$ vs $130{ }^{\circ} \mathrm{C}$ ). As a consequence, the asymmetrical carbonate $2 \mathrm{e}$ [ROCOOR': $\mathrm{R}=\mathrm{Et}, \mathrm{R}^{\prime}=\mathrm{MeO}$ $\left(\mathrm{CH}_{2}\right)_{2} \mathrm{O}\left(\mathrm{CH}_{2}\right)_{2}$ ] was used for $\mathrm{N}$-ethylations reported in entries 6 and 10. These reactions proceeded at appreciable rates, only at $150-160^{\circ} \mathrm{C}$, and therefore cannot be carried out with diethyl carbonate (bp $=126-8{ }^{\circ} \mathrm{C}$ ) at atmospheric pressure.

\section{Conclusions}

The reported procedure represents a new general method for one-pot mono-N-alkylations of anilines with organic carbonates in the presence of NaY faujasite. Reaction conditions and workup are simple, safer alkylating agents (organic carbonates) and eco-friendly reusable catalysts (zeolites) are used, ${ }^{18}$ and no additional solvents are required. The methyl- and chemosel ectivities are independent from the polarity of the reaction medium, and a catalyst saturation effect is clearly observable for $\mathrm{Q}<0.5$, for mono-N-methylations with DMC.

\section{Experimental Section}

All compounds used were ACS grade and were employed without further purification. $\mathrm{NaY}$ was from Aldrich, and it was always used without any dehydrating-activating treatment. ${ }^{9,10}{ }^{1} \mathrm{H}$ NMR spectra were recorded on a $400 \mathrm{MHz}$ spectrometer, using $\mathrm{CDCl}_{3}$ with TMS as the internal standard. GLC and GC/MS (70 eV) analyses were run using CPSil8CB and DB5 capillary columns (30 m), respectively.

(18) Under the conditions of Figure $1(Q=1$ and 0.5$)$, at the end of the reactions, the catalyst has been filtered, dried overnight at $70{ }^{\circ} \mathrm{C}$, and reused for five times. No loss of activity has been observed.

(19) Beilstein Database, Registry Numbers (RN) and CAS Numbers: (a) RN 2205846, CAS 932-967. (b) RN 508285; CAS 13519, 75-0. (c) RN 2719774, CAS 4138-40-3. 
Table 2. Selective Mono-N-alkylation of Primary Aromatic Amines with ROCOOR' (2a-e) in the Presence of NaYa

\begin{tabular}{|c|c|c|c|c|c|c|c|c|c|c|c|}
\hline \multirow[b]{2}{*}{ entry } & \multicolumn{2}{|c|}{ reactants } & \multirow[b]{2}{*}{$W^{b}$} & \multirow[b]{2}{*}{$Q^{c}$} & \multirow[b]{2}{*}{$\mathrm{T}\left({ }^{\circ} \mathrm{C}\right)$} & \multirow[b]{2}{*}{$t(\min )$} & \multirow{2}{*}{$\begin{array}{c}\text { Convn } \\
(\%)^{d}\end{array}$} & \multicolumn{3}{|c|}{ products $(\%, \mathrm{GC})^{\mathrm{e}}$} & \multirow{2}{*}{$\begin{array}{l}\text { isolated yields } \\
(\%, A r N H R)^{r e f}\end{array}$} \\
\hline & $\mathrm{p}-\mathrm{XC}_{6} \mathrm{H}_{4} \mathrm{NH}_{2}(\mathrm{~g})$ & ROCOOR' $^{\prime}$ & & & & & & ArNHR & $\mathrm{ArNR}_{2}$ & $\overline{A r N H R}$ & \\
\hline 1 & $X=H(3)$ & $2 \mathbf{a}$ & $1.2: 1$ & $0.5: 1$ & 130 & 210 & 95 & 92 & 2 & 1 & 1a: $90(\mathrm{R}=\mathrm{Me})^{10 \mathrm{c}}$ \\
\hline 2 & & $\mathbf{2 b}$ & & & 126-8 (reflux) & 180 & 100 & 99 & & & 1b: $84(R=E t)^{6 i}$ \\
\hline 3 & $\mathrm{X}=\mathrm{H}(2.5)$ & 2c & $1.1: 1$ & & 130 & 60 & 100 & 100 & & & 1c: $91(R=B n)^{1 c}$ \\
\hline 4 & & 2d & $1.2: 1$ & & 130 & 100 & 100 & 99 & & & 1d: $94(R=\text { allyl })^{7 b-c}$ \\
\hline $5^{f}$ & $\mathrm{X}=\mathrm{p}-\mathrm{Cl}(1)$ & $2 a$ & $2: 1$ & $1: 1$ & 140 & 350 (480) & 81 (87) & $76(80)$ & $5(7)$ & & 1e: $75(R=M e)^{19 a}$ \\
\hline 6 & & $2 e$ & & & 150 & 660 & 93 & 90 & 3 & & If: $82(R=E t)^{19 b}$ \\
\hline 7 & & 2c & $3: 1$ & & 140 & 120 & 100 & $80^{\mathrm{g}}$ & & & 1g: $70(R=B n)^{4 a}$ \\
\hline 8 & & 2d & $5: 1$ & & 130 & 350 & 97 & 92 & 5 & & lh: $82(R=\text { allyl })^{7 c}$ \\
\hline 9 & $\mathrm{X}=\mathrm{p}-\mathrm{NO}_{2}(0.5)$ & $2 \mathbf{a}$ & $3: 1$ & & 160 & 250 & 94 & 87 & 7 & & 1i: $80(\mathrm{R}=\mathrm{Me})^{10 \mathrm{c}}$ \\
\hline 10 & & $2 e$ & $3: 1$ & & 160 & 510 & 95 & 85 & & 10 & 1l: $68(R=E t)^{8 d}$ \\
\hline 11 & & 2c & $3: 1$ & & 150 & 120 & 92 & 92 & & & 1m: $78(R=B n)^{8 d}$ \\
\hline $12^{f}$ & & $2 d$ & $5: 1$ & & 150 & 90 (120) & $83(99)$ & $81(88)$ & $2(11)$ & & In: $78(R=\text { allyl })^{19 c}$ \\
\hline
\end{tabular}

2a: $\mathrm{R}=\mathrm{Me}, \mathrm{R}^{\prime}=\mathrm{MeO}\left(\mathrm{CH}_{2}\right)_{2} \mathrm{O}\left(\mathrm{CH}_{2}\right)_{2} ; \mathbf{2 b}: \mathrm{R}=\mathrm{R}^{\prime}=\mathrm{Et} ; \mathbf{2 c}: \mathrm{R}=\mathrm{R}^{\prime}=\mathrm{PhCH}_{2} ; \mathbf{2 d}: \mathrm{R}=\mathrm{R}^{\prime}=\mathrm{CH}_{2}=\mathrm{CHCH}_{2} ; \mathbf{2 e}: \mathrm{R}=\mathrm{Et}, \mathrm{R}^{\prime}=$ $\mathrm{MeO}\left(\mathrm{CH}_{2}\right)_{2} \mathrm{O}\left(\mathrm{CH}_{2}\right)_{2}$. ${ }^{a} \mathrm{All}$ reactions were carried out without solvent. bW: molar ratio between the carbonate 2 and the amine. ${ }^{\mathrm{c} Q}$ : weight ratio between the zeol ite ( $\mathrm{NaY}$ ) and the amine. ${ }^{\mathrm{d}} \mathrm{Amine}$ conversion determined by GC. eM ono- $\mathrm{N}$-methyl anilines were characterized by ${ }^{1} \mathrm{H}$ NMR, GC/MS, and by comparison to authentic samples. ArNR 2 and ArNHR' were identified by GC/MS. ' $E$ ntries 5 and 12 : data in parentheses refer to a second run. gUnidentified byproducts (20\%) were observed by GC.

Scheme $3^{a}$

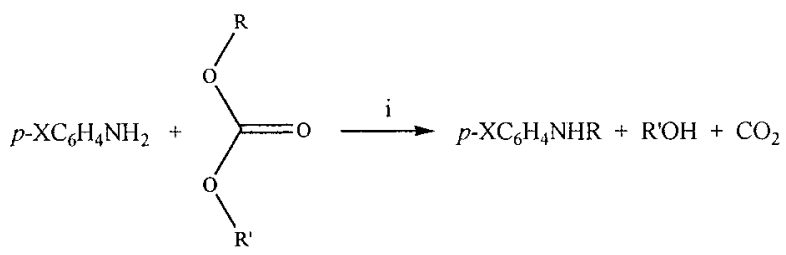

a (i) NaY, $130-160^{\circ} \mathrm{C} . \mathrm{X}=\mathrm{H}, \mathrm{Cl}, \mathrm{NO}_{2} . \mathrm{R}=\mathrm{Me}, \mathrm{R}^{\prime}=\mathrm{Me}, \mathrm{R}^{\prime}=$ $\mathrm{MeO}\left(\mathrm{CH}_{2}\right)_{2} \mathrm{O}\left(\mathrm{CH}_{2}\right)_{2} ; \mathrm{R}=\mathrm{R}^{\prime}=\mathrm{Et} ; \mathrm{R}=\mathrm{R}^{\prime}=\mathrm{PhCH}_{2} ; \mathrm{R}=\mathrm{R}^{\prime}=\mathrm{CH}_{2}$ $=\mathrm{CHCH}_{2} ; \mathrm{R}=\mathrm{Et}, \mathrm{R}^{\prime}=\mathrm{MeO}\left(\mathrm{CH}_{2}\right)_{2} \mathrm{O}\left(\mathrm{CH}_{2}\right)_{2}$. Selectivity in the mono-N-alkylation was $90-97 \%$.

Asymmetrical Carbonates. Characterization data and synthesis of 2-(2-methoxyethoxy)ethyl methyl carbonate $\mathbf{2 a}$ are reported elsewhere. ${ }^{13} 2$-(2-M ethoxyethoxy)ethyl ethyl carbonate $\mathbf{2 e}$ was prepared by transesterification of 2-(2-methoxyethoxy)ethyl alcohol with diethyl carbonate. ${ }^{13} \mathbf{2 e}:{ }^{1} \mathrm{H}$ NMR $\left(\mathrm{CDCl}_{3}\right): \delta 1.29\left(\mathrm{t}, 3 \mathrm{H}, \mathrm{CH}_{3}, \mathrm{~J}=7.18 \mathrm{~Hz}\right), 3.37\left(\mathrm{~s}, 3 \mathrm{H}, \mathrm{CH}_{3}\right)$, $3.54\left(\mathrm{~m}, 2 \mathrm{H}, \mathrm{CH}_{2}\right), 3.64\left(\mathrm{~m}, 2 \mathrm{H}, \mathrm{CH}_{2}\right), 3.72\left(\mathrm{~m}, 2 \mathrm{H}, \mathrm{CH}_{2}\right), 4.18$ $\left(\mathrm{q}, 1 \mathrm{H}, \mathrm{CH}_{2}, \mathrm{~J}=7.18 \mathrm{~Hz}\right), 4.28\left(\mathrm{~m}, 2 \mathrm{H}, \mathrm{CH}_{2}\right)$; mass spectrum (70 eV): $\mathrm{m} / \mathrm{z}(\%): 192,(\mathrm{M}+,<1), 117\left(\left[\mathrm{M}-\mathrm{CH}_{3} \mathrm{O}\left(\mathrm{CH}_{2}\right)_{2} \mathrm{O}\right]^{+}\right.$, 27), $89\left(\left[\mathrm{M}-\mathrm{CH}_{3} \mathrm{O}\left(\mathrm{CH}_{2}\right)_{2} \mathrm{O}\left(\mathrm{CH}_{2}\right)_{2}\right]^{+}, 67\right), 59\left(\left[\mathrm{M}-\mathrm{EtOCO}_{2^{-}}\right.\right.$ $\left.\left.\left(\mathrm{CH}_{2}\right)_{2} \mathrm{O}\right]^{+}, 83\right), 58(72), 45\left(\left[\mathrm{M}-\mathrm{EtOCO}\left(\mathrm{CH}_{2}\right)_{2} \mathrm{OCH}_{2}\right]^{+}, 100\right)$, $30\left(\left[\mathrm{M}-\mathrm{EtOCO}_{2}\left(\mathrm{CH}_{2}\right)_{2} \mathrm{O}\left(\mathrm{CH}_{2}\right)_{2}\right]^{+}, 30\right) . \mathrm{Bp}=52-54{ }^{\circ} \mathrm{C} / 0.1$.

Selective Mono-N-methylation of Aniline with $2 a$. Table 1. A three-necked, $25 \mathrm{~mL}$ round-bottomed flask fitted with a thermometer, an adapter for the withdrawal of samples, a reflux condenser capped with a $\mathrm{CaCl}_{2}$ tube, and a magnetic bar were loaded with a solution $(5 \mathrm{~mL}, 0.45 \mathrm{M})$ of aniline in triethyleneglycol dimethyl ether [triglyme, $\left.\mathrm{MeO}\left[\left(\mathrm{CH}_{2}\right)_{2} \mathrm{O}\right]_{3} \mathrm{Me}\right]$ and $\mathrm{NaY}(0.2 \mathrm{~g})$ in a weight ratio of 1 with respect to the amine. The organic carbonate $\mathbf{2 a}\left[\mathrm{MeOCO}_{2}\left(\mathrm{CH}_{2}\right)_{2} \mathrm{O}\left(\mathrm{CH}_{2}\right)_{2} \mathrm{OMe}\right]$ was then added in different amounts ranging from 4 (1.5 g, 8.6 $\mathrm{mmol})$ to $1.5(0.57 \mathrm{~g}, 3.2 \mathrm{mmol})$ molar equiv with respect to the aniline (entries $1-6)$. The flask was heated at the desired temperature $\left(115-150{ }^{\circ} \mathrm{C}\right)$, and the reaction mixture was vigorously stirred. At intervals, samples of the reaction mixture were withdrawn and were analyzed by both GC and GC/MS.
A reaction was performed with $\mathrm{K}_{2} \mathrm{CO}_{3}$ catalyst and amine (weight ratio 1:1) (entry 7 ).

Figure 1. The above-described procedure was foll owed also for the experiments reported in Figure 1, with the following differences: (i) $3 \mathrm{~mL}$ of a $1.6 \mathrm{M}$ solution of aniline in triglyme was used; (ii) the carbonate $\mathbf{2 a}$ was al ways used in a 2 molar excess with respect to the amine; (iii) the catalyst ( $\mathrm{NaY}$ ) was added in a 0.1, 0.2, 0.5, and $1(0.045,0.09,0.23$, and $0.44 \mathrm{~g}$, respectively) weight ratio with respect to the aniline.

The Selective Mono-N-alkylation of Primary Aromatic Amines by Organic Carbonates $\mathbf{2 a}-\mathbf{e}$. Table 2. The abovedescribed procedure was followed also for the experiments reported in Table 2, with the following difference: the amine was al ways used neat (without solvent) and mixed directly with the carbonate and the zeolite (in the reported $\mathrm{W}$ and Q ratios). In the case of dibenzyl carbonate $\left(\mathbf{2 d} ; \mathrm{mp} 28-30{ }^{\circ} \mathrm{C}\right)$, the initial solid mixture gave a liquid slurry when heated above $40{ }^{\circ} \mathrm{C}$.

Once the reaction was complete, the mixture was allowed to cool to room temperature. The catalyst was filtered off and carefully washed with acetone $(30 \mathrm{~mL})$. The solution was concentrated on a rotary evaporator. The residual mono- $\mathrm{N}$ alkylated amines were purified by distillation in vacuo (1af) or by column chromatography (19,h, el uant: diethyl ether/ petroleum ether $3: 7 \mathrm{v} / \mathrm{v}$ ). In the case of the nitro derivatives $\mathbf{l i}-\mathbf{n}$, after evaporation, the yellow residue was treated with $\mathrm{n}$-pentane $(20 \mathrm{~mL})$ and kept a few hours at room temperature. Products $\mathbf{1 i}-\mathbf{n}$ precipitated as yellow solids, which were filtered, were washed with cold n-pentane ( $5 \mathrm{~mL})$, and were dried. All products were characterized by ${ }^{1} \mathrm{H} N \mathrm{NR}, \mathrm{GC} / \mathrm{MS}$, and by comparison to authentic samples.

Acknowledgment. Murst (I talian Ministry of University and Scientific and Technological Research) and INCA (Interuniversity Consortium Chemistry for the Environment) are gratefully acknowledged for the financial support.

J 00006728 